\title{
Development of photodynamic therapy regimens that control primary tumor growth and inhibit secondary disease
}

\author{
Madeeha Shams • Barbara Owczarczak • \\ Patricia Manderscheid-Kern • David A. Bellnier • \\ Sandra O. Gollnick
}

Received: 18 November 2013 / Accepted: 3 November 2014 / Published online: 11 November 2014

(c) The Author(s) 2014. This article is published with open access at Springerlink.com

\begin{abstract}
Effective therapy for advanced cancer often requires treatment of both primary tumors and systemic disease that may not be apparent at initial diagnosis. Numerous studies have shown that stimulation of the host immune system can result in the generation of anti-tumor immune responses capable of controlling metastatic tumor growth. Thus, there is interest in the development of combination therapies that both control primary tumor growth and stimulate anti-tumor immunity for control of metastatic disease and subsequent tumor growth. Photodynamic therapy (PDT) is an FDA-approved anticancer modality that has been shown to enhance anti-tumor immunity. Augmentation of anti-tumor immunity by PDT is regimen dependent, and PDT regimens that enhance anti-tumor immunity have been defined. Unfortunately, these regimens have limited ability to control primary tumor growth. Therefore, a two-step combination therapy was devised in which a tumor-controlling PDT regimen was combined with an immune-enhancing PDT regimen. To determine whether the two-step combination therapy enhanced anti-tumor immunity, resistance to subsequent tumor challenge and $\mathrm{T}$ cell activation and function was measured. The ability to control distant disease was also determined. The results showed that the novel combination therapy stimulated antitumor immunity while retaining the ability to inhibit primary tumor growth of both murine colon (Colon26-HA) and mammary (4T1) carcinomas. The combination therapy resulted in enhanced tumor-specific $\mathrm{T}$ cell activation and controlled metastatic tumor growth. These results suggest
\end{abstract}

M. Shams · B. Owczarczak · P. Manderscheid-Kern ·

D. A. Bellnier $\cdot$ S. O. Gollnick $(\bowtie)$

Department of Cell Stress Biology, PDT Center, Roswell Park

Cancer Institute, Elm \& Carlton Sts, Buffalo, NY 14263, USA

e-mail: Sandra.gollnick@ roswellpark.org that PDT may be an effective adjuvant for therapies that fail to stimulate the host anti-tumor immune response.

Keywords Photodynamic therapy $\cdot$ Anti-tumor immunity $\cdot$ Combination therapy $\cdot$ Cancer
Abbreviations
CTL Cytotoxic T lymphocyte
CSFE Carboxyfluorescein triacetate, succinimidyl ester
DAMP Damage-associated pattern protein
HA Hemagglutinin
HPPH 2-[1-Hexyloxyethyl]-2-devinyl
pyropheophorbide-a
IACUC Institute Animal Care and Use Committee
MHC Major histocompatibility complex
PDT Photodynamic therapy
PII Sodium Porfimer
TDLN Tumor-draining lymph node

\section{Introduction}

Cancer is a multi-faceted disease, and although therapeutic outcomes have improved over the decades and single treatment modalities are generally effective at controlling the primary tumor, they have little effect on distant disease. This has led to the development of combination therapies that strive to both control primary tumor growth and activate the host immune system to combat distant disease. Photodynamic therapy (PDT) is an FDA-approved anticancer modality used for treatment of early stage disease and palliation of advanced disease [1]. Treatment is carried out by systemic administration of a photosensitizer that is activated locally with tissue-penetrating visible light, resulting in tumor destruction via oxygen-dependent direct 
tumor cell cytotoxicity, vascular damage, and the initiation of acute local and systemic inflammation. The photosensitizer dose, light dose, and light dose-rate define the PDT regimen [2]. Numerous preclinical and clinical studies have shown that PDT efficacy is dependent upon the presence of an intact immune system [1] and that certain PDT regimens can enhance anti-tumor immunity [3, 4].

PDT-enhanced anti-tumor immunity is mediated by $\mathrm{CD}^{+}$cytotoxic $\mathrm{T}$ cells (CTLs) $[3,4]$ and is accompanied by enhanced CTL-mediated tumor cytotoxicity, formation of immune memory cells, and resistance to subsequent tumor growth [5]. $\mathrm{CD} 8^{+} \mathrm{T}$ cell depletion or tumor cell loss of molecules needed for $\mathrm{CD}^{+} \mathrm{T}$ cell recognition [major histocompatibility complex (MHC) class I molecules] result in reduced PDT efficacy [5-7]. PDT-activated CD8 ${ }^{+}$ $\mathrm{T}$ cells also play a critical role in PDT-mediated control of secondary disease [8]. PDT enhancement of CTL activation and anti-tumor immunity is dependent upon induction of acute inflammation [5].

PDT-induced acute inflammation is characterized by rapid migration of neutrophils into the treated tumor bed and tumor-draining lymph nodes and enhanced expression of pro-inflammatory chemokines and cytokines $[9,10]$. The degree of acute inflammation induced by PDT is regimen dependent and correlates with the degree of vascular damage induced [2]. Henderson et al. [2] demonstrated that PDT regimens that result in rapid cell death (within $1 \mathrm{~h}$ of treatment) and maximal tissue damage cause minimal acute inflammation, presumably because of vascular shut down, which prevents neutrophil infiltration and systemic release of cytokines. In contrast, regimens that cause diffuse tumor damage permit neutrophil infiltration and allow for expression and release of inflammatory mediators critical for enhancement of anti-tumor immunity. However, the diffuse tumor damage caused by these regimens resulted in less effective long-term tumor control.

Combination therapies take advantage of the complementary action of the individual components, thereby potentiating the therapeutic effect. We hypothesized that it would be possible to devise a PDT-only therapy using distinctly different, but complimentary, treatment regimens that in combination would enhanced anti-tumor immunity as well as provide effective control of primary tumor growth. To test this hypothesis, we devised a multi-step local treatment program that was comprised of an immuneenhancing PDT regimen followed by a tumor ablation PDT regimen. Results presented here demonstrate that this program was able to control the growth of murine colon and mammary tumors and to promote anti-tumor immunity that was effective against distant disease. These studies demonstrate that PDT-only therapies can be developed that are effective as both a local therapy for control of primary disease and a systemic therapy for treatment of distant disease.

\section{Materials and methods}

Animals and tumor system

Pathogen-free BALB/c mice were obtained from the NCI; scid mice were obtained from the Roswell Park Department of Laboratory Animal Resources. All mice were female, of $\mathrm{BALB} / \mathrm{c}$ background, and were housed in microisolator cages in a laminar flow unit under ambient light. Six- to ten-week-old animals were inoculated subcutaneously on either the right shoulder with $10^{6}$ Colo26 (murine colon carcinoma) or Colo26 cells transfected with hemagglutinin (HA) cDNA (Colo26-HA; [11]) or in the mammary fat pad with $5 \times 10^{5}$ 4T1 mammary carcinoma cells. Intravenous challenge with tumor cells was performed by injection of exponentially growing tumor cells. The Roswell Park Cancer Institutional Animal Care and Use Committee (IACUC) approved all procedures carried out in this study.

\section{Reagents}

Clinical-grade, pyrogen-free 2-[1-hexyloxyethyl]-2-devinyl pyropheophorbide-a (HPPH) was obtained from the Roswell Park Pharmacy (Buffalo, NY) and reconstituted to $0.4 \mu \mathrm{M}$ in pyrogen-free $5 \%$ dextrose in water (D5W; Baxter Corp., Deerfield, IL). Porfimer sodium (PII) was obtained from Pinnacle Biologics (Bannockburn, IL) and reconstituted in D5W.

\section{In vivo $\mathrm{PDT}$ treatment}

Tumor-bearing mice were injected in the tail vein with $0.4 \mu \mathrm{mol} / \mathrm{kg} \mathrm{HPPH}$ or $5 \mathrm{mg} / \mathrm{kg}$ PII, followed $18-24 \mathrm{~h}$ later by illumination to a total light dose of $48 \mathrm{~J} / \mathrm{cm}^{2}$ or $132 \mathrm{~J} / \mathrm{cm}^{2}$ delivered at a light dose-rate of $14 \mathrm{~mW} / \mathrm{cm}^{2}$ as previously described [2, 5]. Control mice were treated with photosensitizer or light alone. Mice receiving a combination PDT regimen were treated initially with $0.4 \mu \mathrm{mol} / \mathrm{kg} \mathrm{HPPH}$ or $5 \mathrm{mg} /$ $\mathrm{kg}$ PII followed 18-24 h later by light dose of $48 \mathrm{~J} / \mathrm{cm}^{2}$ given at $14 \mathrm{~mW} / \mathrm{cm}^{2} ; 9$ days later, mice were again injected with photosensitizer and tumors were illuminated with light at a dose of $132 \mathrm{~J} / \mathrm{cm}^{2}$ given at $14 \mathrm{~mW} / \mathrm{cm}^{2}$.

\section{Transmission of PDT-activating light through tumor tissue}

Noninvasive reflectance spectroscopy was used to measure the penetration of $665-\mathrm{nm}$ light through subcutaneously implanted Colo26-HA tumors. Light attenuation was determined as previously described [12-15]. Briefly, the diffuse fluence $\Phi$ at $665 \mathrm{~nm}$ was measured at increasing probe separations. The total attenuation $\alpha$ is the slope of $\ln (\mathrm{r} \Phi)$ plotted against $r$, where $r$ is the probe separation in $\mathrm{mm}$ and $\Phi$ is the diffuse $665 \mathrm{~nm}$ fluence escaping from the tumor at $r$ $\mathrm{mm}$ from the light source fiber. 
Tumor response determination

Following treatment, orthogonal diameters of tumors were measured once every 2 days with calipers as previously described [2]. Animals were considered cured if they remained tumor free for 60 days after PDT. Treatment with light alone, at either dose, had no effect on the growth of Colo26-HA or 4T1 tumors.

\section{Flow cytometry}

Auxiliary tumor-draining lymph nodes (TDLNs) or tumors were harvested at the indicated time points, and single cell suspensions were generated [16]. Cells were stained with a panel of monoclonal antibodies (MAbs) to detect specific cell surface antigens (CD8, CD11b, CD25, CD44, CD45, CD69, Ly6C, and Ly6G), as previously described [16]. At least five mice per group were analyzed. For the determination of the absolute number of specific cell populations, the percentage of each population was multiplied by the number of cells recovered from the respective TDLN or tumor.

\section{In Vivo cytotoxicity assay}

In vivo cytotoxic assays were performed as previously described [17]. Briefly, TDLNs were harvested from treated mice 2 days post-PDT and adoptively transferred into naive BALB/c hosts as previously described [5]. Red blood cell depleted spleen cells isolated from naïve mice were used as target cells for the assay. Target cells were prepared by labeling a single cell suspension with PKH26 dye (Sigma, St. Louis, MO) for $4 \mathrm{~min}$ at $2 \mu \mathrm{M}$ according to the manufacturer's instructions. The resulting red population was separated in two equal fractions one of which was labeled with $0.1 \mu \mathrm{M}$ carboxyfluorescein triacetate, succinimidyl ester (CFDA-SE, referred to as CFSE, Molecular Probes) and the other with $1 \mu \mathrm{M}$ CFSE for $2 \mathrm{~min}$. The lower-intensity-labeled fraction was pulsed for $1.5 \mathrm{~h}$ with an irrelevant peptide PA1 [18]; the high-intensity-labeled fraction was pulsed with the Colo26-specific peptide AH1 [19]. Equal cell numbers from both populations were admixed and injected into recipient mice. Twenty-four hours later peripheral blood was collected, RBC were lysed, cells were fixed, and then run on a FACS Calibur flow cytometer. Target cells were distinguished from host cells based on PKH26 staining; PA1 peptide- and AH1 peptide-loaded cells were distinguished from one another based on CFSE staining. Gating on $\mathrm{PKH}_{26}{ }^{+}$cells, specific cytotoxicity was calculated according to the formula:

$(1-[\%$ AH1 cells $/ \%$ positive PA1 cells $]) \times 100 \%$.
Assessment of lung tumor growth

4T1 tumor-bearing mice were treated with PII; $18 \mathrm{~h}$ following PII injection, tumors were treated with immuneenhancing PDT. After 9 days, tumors that had been treated with immune-enhancing PDT regimens were either surgically removed or treated with tumor-controlling PDT. Tumors at an equivalent size to those treated 9 days following the immune-enhancing PDT regimen were treated with PII alone, surgically removed or treated with the tumor-controlling PDT regimen. Fourteen days after the final treatment, the presence of tumors was determined by injection of $1 \mathrm{ml}$ of $15 \%$ India ink (diluted in PBS) which was injected via an incision in the trachea. The lungs were removed from the rib cage, weighed, and placed in Fekete's fixative (61\% ethanol, $3.2 \%$ formaldehyde, $4.1 \%$ acetic acid); lung tumors were counted under a dissecting microscope [20].

\section{Statistical evaluation}

All measured values are presented as mean \pm SEM. Student's $t$ test with Welch's correction was used for comparison between groups in all of the experiments, with the exception of tumor response experiments, which were analyzed using Log-rank (Mantel-Cox) analysis of survival curves. The term "significant" in the text represents a $P$ value equal to or less than 0.05 .

\section{Results}

Long-term tumor growth control following combination PDT

Our previous studies indicated that treatment regimens that led to optimal long-term tumor response elicited only marginal inflammation and limited enhancement of antitumor immunity [2, 5]. These treatment regimens also ablated the tumor vasculature, and treated tumors showed widespread areas of apoptosis that was accompanied by prolonged caspase 3 activation. In contrast, regimens that elicited acute inflammation and strong anti-tumor immunity preserved the tumor vasculature, resulted in minimal long-term tumor growth control, limited areas of apoptosis, and transient caspase 3 activation. Therefore, we refer to these treatments as immune enhancing, while those regimens that effectively control tumor growth, but result in minimal enhancement of anti-tumor immunity, are referred to as tumor-controlling regimens. We hypothesized that treating tumors with an immune-enhancing PDT regimen followed by a tumor-controlling PDT regimen could lead to enhancement of anti-tumor immunity, 
while retaining effective control of primary tumor growth. To test this hypothesis, a combination treatment regimen was devised in which Colo26-HA tumor-bearing BALB/c mice were treated with a HPPH-PDT regimen known to lead to enhanced anti-tumor immunity $(0.4 \mu$ moles $/ \mathrm{kg}$ HPPH followed $18 \mathrm{~h}$ later by illumination with $665 \mathrm{~nm}$ light for a total dose of $48 \mathrm{~J} / \mathrm{cm}^{2}$ [5]). Following illumination, mice were rested for 9 days; on the ninth day, mice were injected with HPPH. On day 10 following the first treatment, tumors were treated with a tumor control treatment regimen (illumination with $665 \mathrm{~nm}$ light for a total dose of $132 \mathrm{~J} / \mathrm{cm}^{2}$ given [5]).

PDT efficacy depends on the intensity and distribution of light in the tumor. We were concerned that the initial PDT exposure might change the optical properties of the tumor tissue and perturb the effectiveness of the subsequent PDT exposure. Therefore, we measured light transmission through Colo26-HA tumors immediately before both the first and the second PDT treatments and compared their calculated optical penetration depths (characterized by $\delta$, the distance over which diffuse light decreases in intensity to $1 / \mathrm{e}$ or $37 \%$ of its initial value) through tumor tissue. Light penetration measured immediately before the second PDT treatment was slightly greater than that determined before the first PDT treatment $\left(\delta_{\mathrm{PDT} 1}=2.80 \mathrm{~mm}\right.$, $\delta_{\mathrm{PDT} 2}=3.06 \mathrm{~mm}$ ), but that difference was not statistically significant. Thus, prior treatment with an immune-enhancing PDT regimen does not alter the optical properties of the tumor tissue.

We next tested whether prior treatment with an immuneenhancing PDT regimen altered effectiveness of tumorcontrolling PDT regimens. Colo26-HA tumor-bearing mice were treated with the combination therapy (immuneenhancing PDT followed 10 days later with tumor-controlling PDT). Animals bearing tumors of an equivalent size to the regrowing tumors present in the animals treated initially with immune-enhancing PDT at the time of the second HPPH injection ( 9 days following delivery of the initial immune-enhancing PDT regimen) were also injected with $\mathrm{HPPH}$ and were treated $18 \mathrm{~h}$ later with the tumor control PDT regimen or were treated with $665 \mathrm{~nm}$ light for a total dose of $48 \mathrm{~J} / \mathrm{cm}^{2}$ or $135 \mathrm{~J} / \mathrm{cm}^{2}$. Tumor growth was monitored for 60 days (Fig. 1a). All treatments resulted in significant tumor control when compared to the control treatment with either HPPH or light alone $(P \leq 0.001)$; for simplicity sake, the tumor growth response of tumors treated with light alone is not depicted. The combination treatment controlled tumor growth as well as the single treatment at $132 \mathrm{~J} / \mathrm{cm}^{2}(P \leq 0.4)$ and significantly better than treatment with $48 \mathrm{~J} / \mathrm{cm}^{2}(P \leq 0.001)$. Thus, demonstrating that prior treatment of tumors with an immune-enhancing regimen did not affect tumor growth control by the optimal tumor growth control treatment regimen.
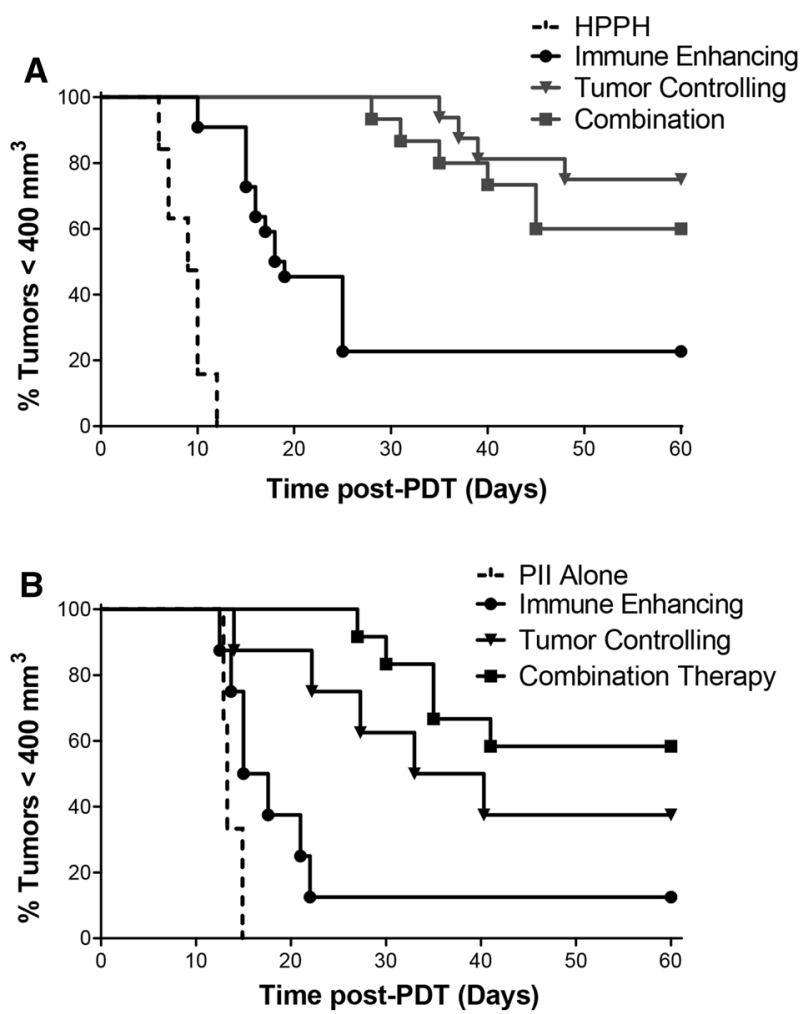

Fig. 1 Long-term tumor growth controlfollowing combination therapy. Colo26-HA tumor-bearing mice were injected systemically with $\mathrm{HPPH}(\mathbf{a} ; 0.4 \mu \mathrm{mol} / \mathrm{kg})$ or PII $(\mathbf{b} ; 5 \mathrm{mg} / \mathrm{kg}) ; 18-24 \mathrm{~h}$ later, mice were subjected to PDT at a total dose of $48 \mathrm{~J} / \mathrm{cm}^{2}$. Nine days later, treated mice were randomly divided into two groups. One group was injected systemically with HPPH $(\mathbf{a} ; 0.4 \mu \mathrm{mol} / \mathrm{kg})$ or PII $(\mathbf{b} ; 5 \mathrm{mg} / \mathrm{kg})$; tumor growth was monitored in the second group, which represents the immune-enhancing treatment group. Control mice bearing Colo26HA tumors of equal size to those regrowing in mice that had been previously treated with PDT at a dose of $48 \mathrm{~J} / \mathrm{cm}^{2}$ were also injected systemically with HPPH or PII; 18-24 h later, control mice were left untreated (HPPH or PII alone) or treated with PDT $\left(132 \mathrm{~J} / \mathrm{cm}^{2}\right.$; tumor-controlling regimen). Mice that had been previously treated with PDT at a dose of $48 \mathrm{~J} / \mathrm{cm}^{2}$ were retreated with PDT at a dose of $132 \mathrm{~J} / \mathrm{cm}^{2}$ (combination). Each group contained a minimum of eight animals. Tumor growth was followed until tumors reached $400 \mathrm{~mm}^{3}$ or 60 days

To determine whether the results obtained were limited to a specific photosensitizer, the two-step combination therapy was performed using sodium Porfimer (PII) as the photosensitizer. Colo26-HA tumor-bearing mice were treated as above except that PII $(5 \mathrm{mg} / \mathrm{kg})$ was used in place of HPPH as the photosensitizer. Colo26-HA tumors responded similarly to PII-PDT as they did to HPPH-PDT (Fig. 1b). Minimal but significant tumor efficacy was observed following treatment with the immune-enhancing PII-PDT regimen (48 J/ $\left.\mathrm{cm}^{2} ; P \leq 0.05\right)$; treatment with either the tumor-controlling PII-PDT treatment regimen $\left(132 \mathrm{~J} / \mathrm{cm}^{2}\right)$ or the two-step combination therapy resulted in increased tumor growth control that was significantly 

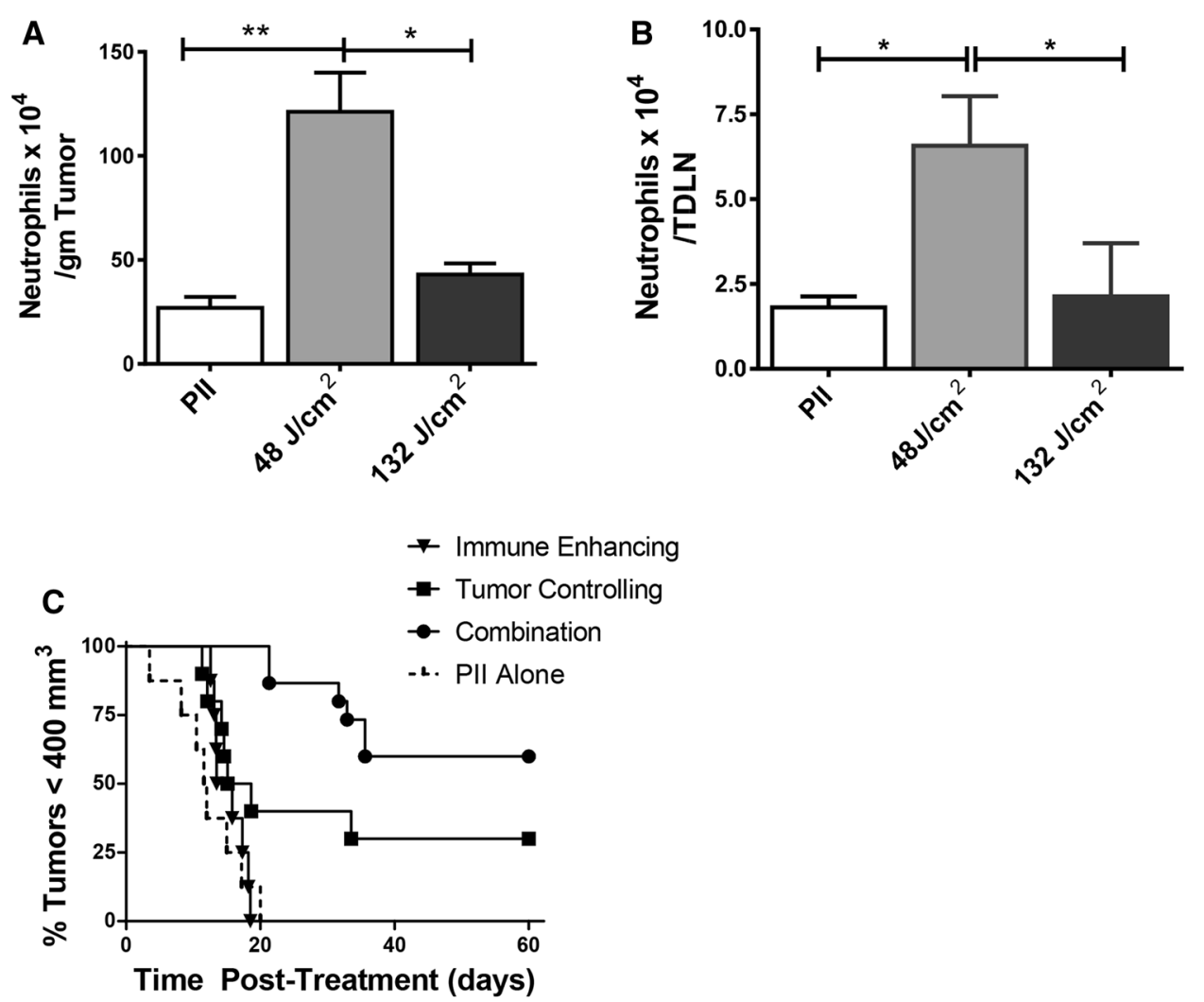

Fig. 2 Combination therapy increases long-term tumor growth control. a, b $4 \mathrm{~T} 1$ tumor-bearing mice were treated with PII-PDT $(5 \mathrm{mg} /$ $\mathrm{kg}$ PII) doses of 48 or $132 \mathrm{~J} / \mathrm{cm}^{2}$. Control animals were treated with PII alone. Each group contained a minimum of five animals. Tumors (a) and tumor-draining lymph nodes (TDLN; b) were collected $4 \mathrm{~h}$ after the final treatment. Single cell suspensions were generated, and the number of neutrophils $\left(\mathrm{CD} 45^{+} \mathrm{CD} 11 \mathrm{~b}^{+} \mathrm{Ly} 6 \mathrm{C}^{+} \mathrm{Ly} 6 \mathrm{G}^{\mathrm{Hi}}\right) / \mathrm{gm}$ of tumor (a) or $\left(\mathrm{CD} 11 \mathrm{~b}^{+} \mathrm{Ly} 6 \mathrm{C}^{+} \mathrm{Ly} 6 \mathrm{G}^{\mathrm{Hi}}\right) / \mathrm{TDLN}$ (b) was determined. Error bars represent SEM. $* P \leq 0.05 ; * * P \leq 0.01$ (c) $4 \mathrm{~T} 1$ tumorbearing mice were injected systemically with PII $(5 \mathrm{mg} / \mathrm{kg}$ PII); 18-24 h later, mice were subjected to PDT at a total dose of $48 \mathrm{~J} /$ $\mathrm{cm}^{2}$. Nine days later, treated mice were randomly divided into two

greater than that observed with either PII treatment alone or treatment with the low-dose PDT regimen $(P \leq 0.003$ or $P \leq 0.04$, respectively). There was no significant difference in tumor growth control between treatment with the high-dose PDT regimen and the two-step combination therapy.

The two-step combination therapy was also tested in the 4T1 mammary carcinoma model. Neutrophil mobilization into tumor tissue is a characteristic of PDT-induced acute inflammation [5, 21]; neutrophil mobilization into tumor-draining lymph nodes (TDLNs) is required for PDT enhancement of anti-tumor immunity [5]. Therefore, neutrophil mobilization into tumors and TDLNs was examined following PDT of orthotopically growing 4T1 mammary carcinomas. 4T1 tumor-bearing mice were treated with PIIPDT $(5 \mathrm{mg} / \mathrm{kg}$ PII followed $18 \mathrm{~h}$ later by illumination with groups. One group was injected systemically with PII $(5 \mathrm{mg} / \mathrm{kg})$; tumor growth was monitored in the second group, which represents the immune-enhancing treatment group. Control mice bearing 4T1 tumors of equal size to those regrowing in mice that had been previously treated with PDT at a dose of $48 \mathrm{~J} / \mathrm{cm}^{2}$ were also injected systemically with PII; 18-24 h later, control mice were left untreated (PII alone) or treated with PDT $\left(132 \mathrm{~J} / \mathrm{cm}^{2}\right.$; tumor-controlling regimen). Mice that had been previously treated with PDT at a dose of $48 \mathrm{~J} / \mathrm{cm}^{2}$ were retreated with PDT at a dose of $132 \mathrm{~J} / \mathrm{cm}^{2}$ (combination). Each group contained a minimum of eight animals. Tumor growth was followed until tumors reached $400 \mathrm{~mm}^{3}$ or 60 days

$630 \mathrm{~nm}$ light for a total dose of either $48 \mathrm{~J} / \mathrm{cm}^{2}$ or $132 \mathrm{~J} /$ $\mathrm{cm}^{2}$ delivered at $14 \mathrm{~mW} \mathrm{~cm}$ ); the number of infiltrating neutrophils present $4 \mathrm{~h}$ post-treatment in the tumor bed and TDLN was determined by flow cytometry. Neutrophils were identified as those $\mathrm{CD} 45^{+} \mathrm{CD} 11 \mathrm{~b}^{+}$cells (tumor) or CD11 $\mathrm{b}^{+}$cells (TDLN) expressing Ly6C and high levels of Ly6G [22]. Treatment of 4T1 tumors with a PII-PDT regimen of $48 \mathrm{~J} / \mathrm{cm}^{2}$ led to a significant increase in the number of neutrophils present in the treated tumor bed (Fig. 2a) and TDLN (Fig. 2b) when compared to the number of neutrophils present in tumors or TDLN of animals treated with PII alone ( $P \leq 0.01 ; P \leq 0.03$, respectively). In contrast, treatment with $132 \mathrm{~J} / \mathrm{cm}^{2}$ resulted in a negligible increase in neutrophils in either the tumor bed or TDLN $(P \leq 0.1)$. Based upon these findings, we have defined the $48 \mathrm{~J} / \mathrm{cm}^{2}$ treatment as immune enhancing. 


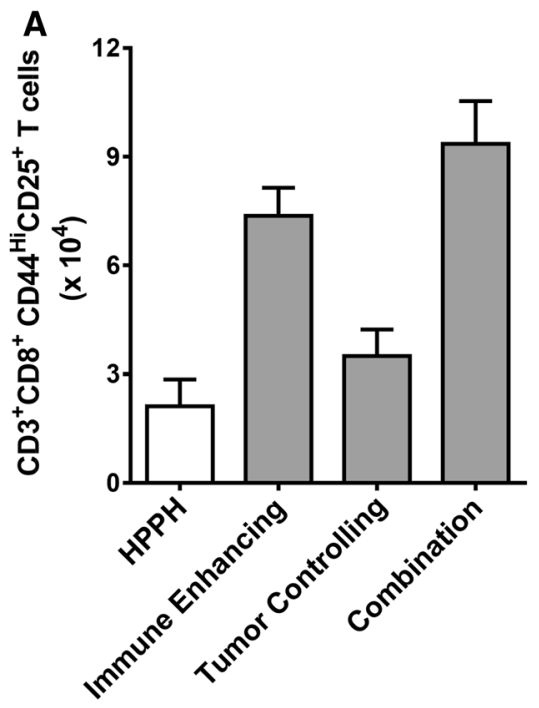

Fig. 3 Combination therapy increases T cell activation. Colon26-HA tumor-bearing mice were treated with HPPH or HPPH-PDT $(0.47$ $\mu$ moles $/ \mathrm{kg} \mathrm{HPPH})$ immune-enhancing $\left(48 \mathrm{~J} / \mathrm{cm}^{2}\right)$, tumor-controlling $\left(132 \mathrm{~J} / \mathrm{cm}^{2}\right)$ or a combination regimen of immune-enhancing treatment followed by tumor-controlling treatment as described in Fig. 1. a TDLNs were collected $24 \mathrm{~h}$ after the final treatment, and single cell suspensions were generated. The number of activated $\mathrm{CD} 8^{+} \mathrm{T}$ cells

We then examined the effect of PDT regimens on 4T1 tumor growth. 4T1 tumor-bearing mice were treated as above with PII alone, light alone $(630 \mathrm{~nm}$ for a total dose of $48 \mathrm{~J} / \mathrm{cm}^{2}$ or $135 \mathrm{~J} / \mathrm{cm}^{2}$ delivered at $14 \mathrm{~mW} / \mathrm{cm}^{2}$ ) or PII-PDT $(5 \mathrm{mg} / \mathrm{kg}$ PII followed $18 \mathrm{~h}$ later by illumination with $630 \mathrm{~nm}$ light for a total dose of either $48 \mathrm{~J} /$ $\mathrm{cm}^{2}$ or $132 \mathrm{~J} / \mathrm{cm}^{2}$ ), or with a two-step combination therapy in which $4 \mathrm{~T} 1$ tumor-bearing mice were treated with immune-enhancing PDT followed 10 days later with treatment with the higher-dose PDT regimen $(5 \mathrm{mg} /$ $\mathrm{kg}$ PII given 9 days after the first treatment, followed 18-24 h later with illumination with $630 \mathrm{~nm}$ light for a total dose of $132 \mathrm{~J} / \mathrm{cm}^{2}$ delivered at $14 \mathrm{~mW} \mathrm{~cm}{ }^{2}$ ). Tumor growth following treatment was monitored for 60 days or until the primary tumor reached $400 \mathrm{~mm}^{3}$. Treatment of 4T1 tumors with the immune-enhancing PII-PDT regimen did not lead to long-term tumor growth control ( $P \geq 0.05$ compared to treatment with PII alone); treatment with $132 \mathrm{~J} / \mathrm{cm}^{2}$ resulted in marginal, but significant control of tumor growth $(P \leq 0.05 ;$ Fig. $2 c)$. This was the optimal tumor growth control achieved when the fluence rate was held to $14 \mathrm{~mW} / \mathrm{cm}^{2}$ (data not shown). Therefore, the $132 \mathrm{~J} / \mathrm{cm}^{2}$ treatment was identified as tumor controlling. Interestingly, when the treatments were combined, there was a significant increase in long-term tumor growth control as compared to treatment with $132 \mathrm{~J} / \mathrm{cm}^{2}$ $(P \leq 0.05)$.

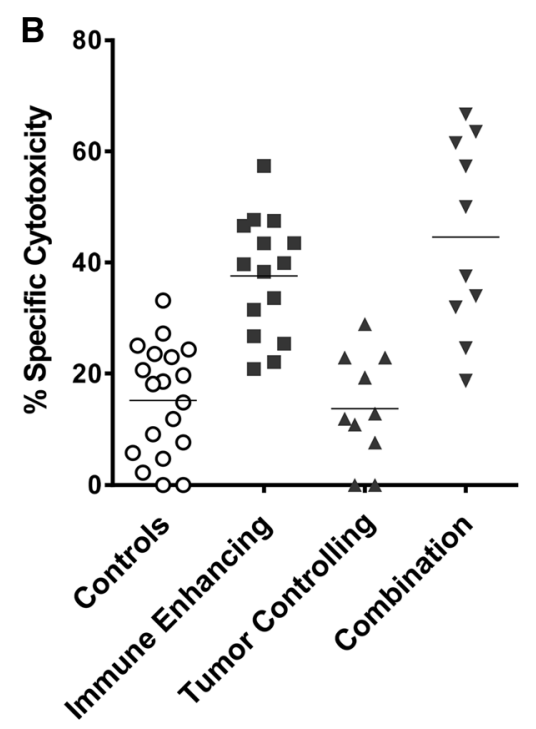

$\left(\mathrm{CD} 3{ }^{+} \mathrm{CD} 8{ }^{+} \mathrm{CD} 44^{\mathrm{Hi}} \mathrm{CD} 25^{+}\right)$was determined by flow cytometry. A minimum of 14 mice were examined in each group. b TDLNs were collected $24 \mathrm{~h}$ after the final treatment, and in vivo cytotoxicity assays were performed as described in Materials and Methods. Results are presented as \% specific cytotoxicity. Each symbol represents results obtained from an individual mouse; horizontal lines represent the median. A minimum of ten mice were examined per group

Combination PDT regimen leads to enhanced anti-tumor T cell activation and activity

Previous studies have shown that activated T cells are susceptible to PDT [23], and it is possible that T cells activated in response to immune-enhancing PDT regimens would be deleted by subsequent PDT regimens. Therefore, we examined the effect of the combination PDT regimen on $\mathrm{T}$ cell activation. Colo26-HA tumor-bearing BALB/c mice were treated with immune-enhancing, tumor-controlling or combination PDT regimens. Two days following the final treatment, tumor-draining lymph node (TDLN) cells were examined by flow cytometry for the presence of activated, proliferating $\mathrm{CD} 8^{+} \mathrm{T}$ cells, which were defined as $\mathrm{CD}^{+}$cells that express CD25 and high levels of CD44. As observed previously [5], treatment of Colo26-HA tumors with immune-enhancing PDT regimen resulted in significantly increased numbers of activated and proliferating $\mathrm{CD}^{+} \mathrm{T}$ cells $(P \leq 0.01)$, while treatment with the tumorcontrolling PDT regimen had minimal effect on the numbers of activated $\mathrm{CD} 8^{+} \mathrm{T}$ cells compared to $\mathrm{CD} 8^{+} \mathrm{T}$ cells isolated from animals treated with HPPH alone $(P \leq 0.2$; Fig. 3a). Treatment with the combination therapy also led to significantly increased numbers of activated, proliferating $\mathrm{CD}^{+} \mathrm{T}$ cells compared to either $\mathrm{CD} 8^{+} \mathrm{T}$ cells isolated from animals treated with HPPH or tumor-controlling PDT $(P \leq 0.01)$; the increase in activated, proliferating $\mathrm{CD}^{+}$ 
$\mathrm{T}$ cells following the combination therapy was not significantly different from the increase induced by the immuneenhancing PDT regimen $(P \leq 0.2)$. Similar results were obtained following treatment of 4T1 tumor-bearing mice (data not shown).

We have previously demonstrated that the increased number of activated and proliferating $\mathrm{T}$ cells following treatment of Colo26-HA tumor with immune-enhancing PDT regimens leads to increased lysis of target cells loaded with peptides derived from either the surrogate antigen, HA, or gp70, an endogenous tumor antigen expressed by Colo26-HA and the parental Colo26 tumor cell lines [5, 19]. To determine whether the increase in $\mathrm{CD} 8^{+} \mathrm{T}$ cell accumulation observed following the combination treatment was also associated with increase cell lysis, the ability of PDT-activated lymph node cells to eliminate target cells loaded with tumor-associated peptides was measured in vivo. TDLN cells were harvested from treated mice 2 days following the last PDT treatment and adoptively transferred into naïve $\mathrm{BALB} / \mathrm{c}$ mice. Recipient mice were then challenged with an i.v. injection of cells primed with AH1 peptide, which is the immunodominant peptide from gp70 [19] or a control peptide. Recipient mice adoptively transferred with TDLN cells isolated from mice treated with immuneenhancing and combination treatment regimens exhibit significantly increased specific cytotoxicity against cells bearing tumor-specific peptides when compared to recipient mice receiving TDLN cells from control mice or mice treated with the tumor-controlling PDT regimen (Fig. 3b; $P \leq 0.001)$. As predicted and previously observed, recipient mice receiving TDLN cells from mice treated with tumorcontrolling PDT regimens exhibited minimal cytotoxicity against cells expressing tumor-specific peptides. The lack of a known tumor antigen expressed by $4 \mathrm{~T} 1$ tumors prevented us from carrying out similar assays in this model.

Combination PDT regimen results in increased resistance to tumor challenge

To determine whether increased cytotoxicity against tumor antigens translated to increased resistance to tumors, mice that remained tumor free for 60 days after the final PDT treatment were challenged with Colo26 cells. Colo26 cells were used in these experiments rather than Colo26-HA cells in order to validate the results obtained from the in vivo cytotoxicity experiments (Fig. 3b) and to further confirm that PDT enhancement of anti-tumor immunity was not restricted to immunity against over-expressed surrogate antigens as was demonstrated by Mroz et al. [24]. We have shown previously that the tumor response of parental Colo26 tumors and Colo26-HA tumors to HPPH-PDT is indistinguishable [5]. Colo26-HA tumor-bearing mice that remained tumor free following treatment with either
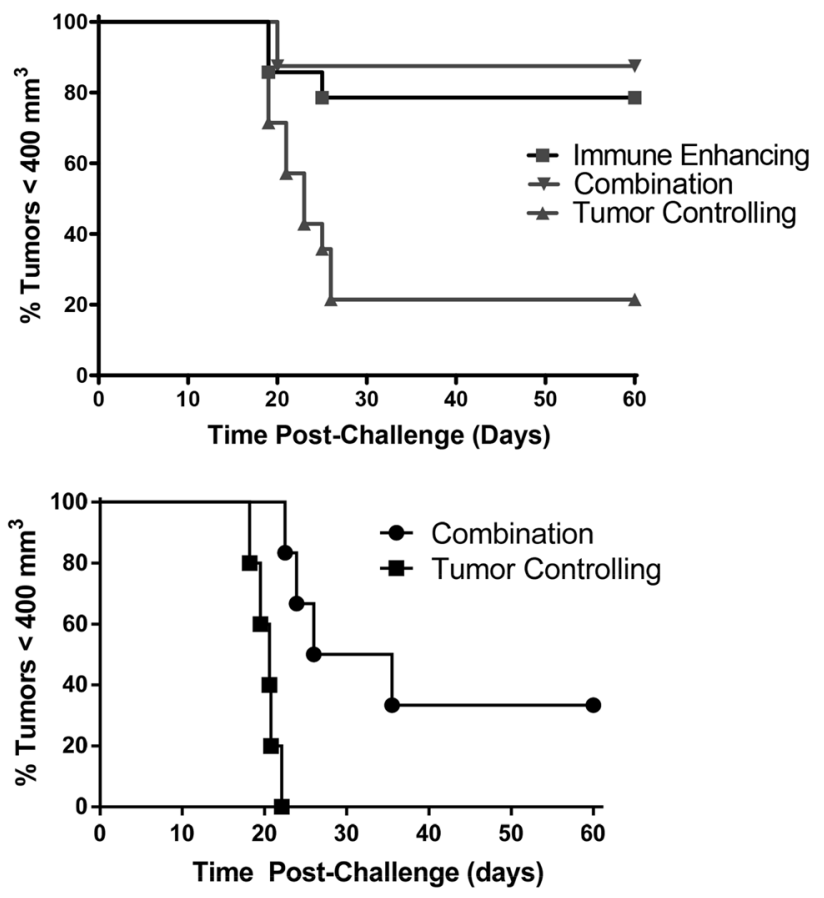

Fig. 4 Combination therapy increases resistance to tumor challenge. Colo26-HA or 4T1 tumor-bearing mice were treated with tumorcontrolling, immune-enhancing, or the combination HPPH- or PIIPDT regimens, respectively, as described in Figs. 1 and 2. Mice that remained tumor-free 40 days after treatment were challenged with live tumor cells (a: Colon 26 challenge; b: $4 \mathrm{~T} 1$ challenge). Tumor growth was monitored for 60 days or until tumors reached $400 \mathrm{~mm}^{3}$

immune-enhancing or combination regimens were more resistant to subsequent challenge with Colo26 cells than mice that remained tumor free following treatment with tumor--controlling PDT regimens $(P \leq 0.01$; Fig. $4 \mathrm{a})$, confirming that enhancement of anti-tumor immunity was not solely due to enhanced recognition of the surrogate antigen HA. Greater than $60 \%$ of mice treated with the tumorcontrolling PDT regimen remained tumor free for 60 days; however, less than $20 \%$ of these mice were able to resist a subsequent tumor challenge. Similarly, 4T1 tumor-bearing mice whose tumors were eradicated by treatment with the combination therapy were better able to resist subsequent tumor challenge when compared to mice whose tumors were treated with $132 \mathrm{~J} / \mathrm{cm}^{2}$ (Fig. $4 \mathrm{~b} ; P \leq 0.01$ ). Since the immune-enhancing treatment regimen did not eradicate 4T1 tumors in any animals, it was not possible to measure subsequent resistance to $4 \mathrm{~T} 1$ tumor challenge in animals treated with immune-enhancing PDT regimens.

The increase in effectiveness and anti-tumor immunity observed following treatment of $4 \mathrm{~T} 1$ tumors with the combination therapy suggests that this treatment regimen may control metastatic tumor growth. The $4 \mathrm{~T} 1$ tumor rapidly metastasizes to the lung [25]. To assess the effect of PDT regimens on metastasis, 4T1 tumor-bearing mice were 


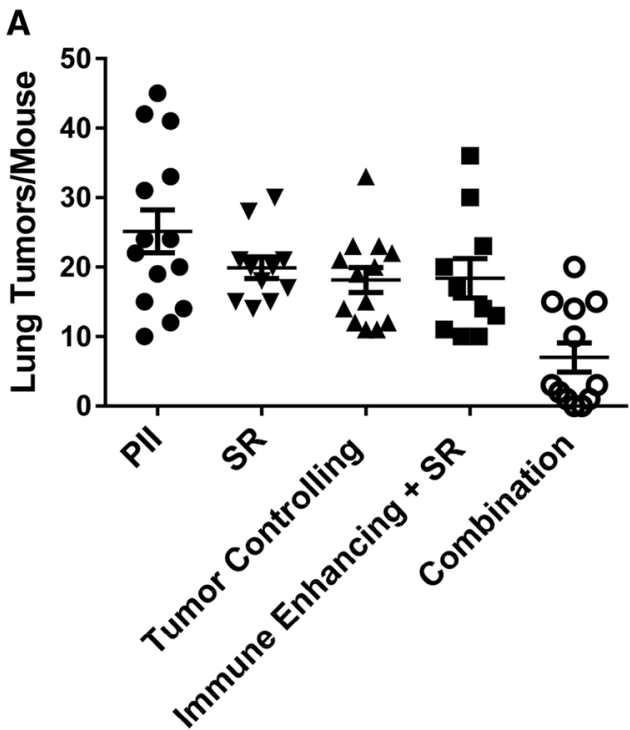

Fig. 5 Combination therapy reduces 4T1 lung metastases. 4T1 tumor-bearing BALB/c $(\mathbf{a}+\mathbf{b})$ or scid $(\mathbf{b})$ mice were treated with immune-enhancing PDT as described in Fig. 2. After 9 days, treated mice were re-injected with PII $(5 \mathrm{mg} / \mathrm{kg}) ; 18-24 \mathrm{~h}$ later tumors were either surgically removed (Immune Enhancing + SR) or treated with tumor-controlling PDT (combination). Tumors at an equivalent size to those present in mice treated 10 days prior with the immuneenhancing PDT regimen were treated with PII alone, surgically removed $(\mathrm{SR})$ or treated with the tumor-controlling PDT regimen

treated with immune-enhancing PDT. After 9 days, mice that had been treated with immune-enhancing PDT regimens were injected with PII. The following day, previously treated tumors were either surgically removed (Immune Enhancing + SR) or retreated with tumor-controlling PDT (Combination). Tumors at an equivalent size to those present in mice treated 10 days prior with the immune-enhancing PDT regimen were treated with PII alone, surgically removed (SR) or treated with the tumor-controlling PDT regimen (Tumor Controlling). Lungs were collected from the treated and control mice 14 days later, and the number of metastases/lung was determined (Fig. 5a).

Neither surgical removal of 4T1 tumors, treatment with tumor-controlling PDT, nor treatment with immuneenhancing PDT regimen followed by surgical removal of tumors had a significant effect on the number of tumors present in the lung when compared to treatment with PII alone. In contrast, treatment with the combination therapy significantly reduced the number of tumors present in the lung compared to all other treatments tested $(P \leq 0.02)$.

To determine whether the reduction in lung metastases observed following the combination therapy was a result of enhanced anti-tumor immunity, the combination treatment was carried out in immune-compromised scid mice (Fig. 5b). No significant difference was observed between the numbers of lung tumors present in immune-competent
B

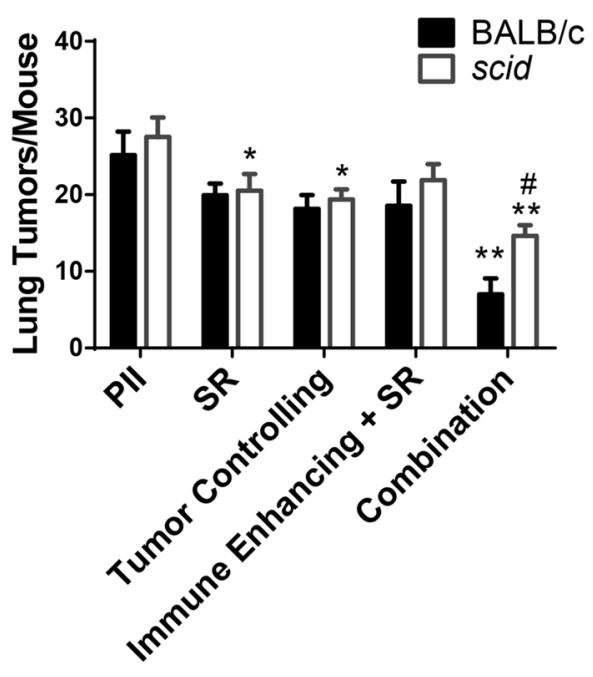

(tumor controlling). Lungs were collected 14 days later, and the number of metastases/lung was determined. a Results represent the number of tumors tumors/mouse. Each symbol represents an individual mouse. The mean is represented by a line, and the error bars represent the SEM. Each group contains a minimum of ten mice. b Results represent the average number of lung tumors/mouse. Error bars represent SEM; each group contains a minimum of ten mice. ${ }^{*} P \leq 0.05$, ${ }^{* *} P \leq 0.001$ when compared to treatment with PII alone; ${ }^{\#} P \leq 0.05$ when compared to BALB/c

$\mathrm{BALB} / \mathrm{c}$ versus the number present in immune-compromised scid mice 14 days after surgical removal of the primary 4T1 tumor or treatment of the primary tumor with either PII alone, tumor-controlling PDT, or immune-enhancing PDT followed by surgical removal of the primary tumor. However, surgical removal and treatment of the primary tumor with the tumor-controlling PDT regimen did significantly reduce the number of lung tumors present in scid mice when compared to treatment with PII alone $(P \leq 0.05)$. Thus, it appears as though the reduction in lung tumors observed following surgical removal of the primary tumors or treatment of the primary tumors with tumor-controlling PDT was not a result of enhanced anti-tumor immunity.

The number of lung tumors present in scid mice was significantly higher than those present in BALB/c mice following treatment of primary 4T1 tumors with the combination PDT regimen (Fig. 5b; $P \leq 0.03$ ); suggesting that anti-tumor immunity plays a role in control of metastatic tumor growth following treatment. However, the combination therapy was still able to control metastatic growth in the absence of a functioning adaptive immune system as the number of lung tumors present in scid mice following the combination therapy was significantly lower than the number of lung tumors present following surgical removal of the primary tumor $(P \leq 0.04)$ or treatment or the primary tumor with PII alone $(P \leq 0.0002)$, tumor-controlling 
PDT ( $P \leq 0.02$ ), or immune-enhancing PDT followed by surgical removal of the primary tumor $(P \leq 0.01)$.

\section{Discussion}

Recent studies have shown that the host response to PDT is influenced by the treatment parameters [2] and that treatments of different parameters can be used to in combination to achieve desirable outcomes [26]. In the current study, we combine an immune-enhancing PDT regimen with a tumor growth-controlling PDT regimen in order to develop a single modality combination therapy that would both control primary tumor growth and stimulate the host immune system to modulate growth of distant disease. Treatment of tumor-bearing mice with this novel combination therapy resulted in efficacious tumor growth control, increased numbers of activated $\mathrm{CD}^{+}$ $\mathrm{T}$ cells and tumor-specific cytotoxicity, and an increased in resistance to subsequent tumor challenge and metastatic tumor growth. Enhancement of anti-tumor immunity by the combination treatment regimen occurred when either HPPH- or PIIPDT was used. Additionally, colon and mammary carcinoma models exhibited regimen-dependent host responses. This suggests that these findings may be applicable across photosensitizers and that it may be possible to identify immune-enhancing PDT regimens in multiple tumor models.

The mechanism of the dose-dependent induction of inflammation and subsequent enhancement of anti-tumor immunity by PDT is unclear. Previous studies by Henderson et al. [2] have suggested that treatment of tumors with high-dose PDT regimens result in vascular ablation that prevents infiltration of the tumor bed by innate immune cell and limits acute inflammation. Initiation of inflammation and subsequent stimulation of anti-tumor immunity have been linked to the recognition of alarmins by innate immune cells [27, 28]. Alarmins include damage-associated pattern proteins (DAMPs) and metabolites released or expressed on the cell surface by damaged and transformed cells, as well as cytokines such as IL- $1 \alpha$. Alarmins are released following PDT and have been linked to generation of inflammation and anti-tumor immunity [29-32]. Recent studies by Tracy et al. [33] have demonstrated that PDT dose influences the release of alarmins. Significantly at high doses, in vitro PDT treatment of tumor cells leads to an inactivation of alarmins and a reduction in the release of inflammatory mediators by stromal cells. In contrast, Garg et al. [34] showed that expression of a cell surfaceassociated DAMP, calreticulin, increased with PDT dose; however, the ability of ecto-calreticulin induced by highdose PDT to induce inflammation was not tested.

Once activated in the lymph node, $\mathrm{CD}^{+} \mathrm{T}$ cells become either effector or memory cells [35]. Effector cells leave the lymph node and migrate to the tumor site [36]; memory cells migrate to secondary lymphoid organs (central memory $\mathrm{T}$ cells) or non-lymphoid tissues (effector memory T cells) [36, 37]. We have previously shown that there is an increase in activated tumor-specific $\mathrm{CD}^{+} \mathrm{T}$ cells in the treated tumor bed 7 days after treatment with the immune-enhancing PDT regimen [5]. Activated, proliferating T cells are susceptible to PDT [23]; therefore, it was possible that treatment of tumors with a second PDT regimen 10 days after treatment with the immune-enhancing PDT regimen would result in elimination of tumor-specific T cells, which may prevent resistance to subsequent tumor challenge. However, mice treated with the combination therapy were able to control tumor growth when challenged 60 days following treatment, demonstrating a persistence of anti-tumor immunity and strongly suggesting the presence of long lived memory T cells.

Importantly, the enhancement of immune reactivity to Colo26 tumors by either the immune-enhancing or combination PDT regimens was not limited to recognition of an over-expressed surrogate antigen, confirming our previous preclinical and clinical studies demonstrating that PDT enhances immune recognition of endogenous tumor antigens [5, 38]. Similarly, Mroz et al. [39] showed that vascular PDT regimens enhanced immune reactivity against the endogenous cancer/testis antigen PA1; although this treatment regimen was unable to augment anti-tumor immunity against endogenous tumor antigens in Colo26 tumors.

Treatment of either the colon or mammary tumor model with the combination therapy resulted in effective control of primary tumor growth; in the case of the Colo26-HA tumor model, there was no significant difference in primary tumor growth following treatment with the tumor growth-controlling PDT regimen and the combination therapy regardless of the photosensitizer used. In contrast, the combination therapy controlled primary 4T1 tumor growth significantly better than single treatment with the tumorcontrolling PDT regimen. The reason for this difference is unclear. One possibility is that although tumor size was controlled such that the tumors treated with the single dose of tumor-controlling PDT regimen were of similar size to those treated 10 days following the immune-controlling PDT regimen in the combination therapy, the immune-controlling PDT regimen sensitized the orthotopic tumors to PDT in some manner. The immune-controlling PDT regimen induces a strong local inflammatory response, which could be responsible for this alteration. Studies are currently underway to address this possibility.

Orthotopic 4T1 tumors rapidly metastasize to the lung and liver within 21 days of inoculation [25]. We and others have previously shown that PDT-enhanced anti-tumor immunity can control distant disease [8, 40-42]. The combination therapy was also able to control 4T1 tumor metastases; although the control was not entirely dependent upon the immune system as control was significantly but not 
completely ablated when the combination therapy was performed in scid mice. Metastatic tumor growth was also partially controlled following surgical removal of the primary tumor and treatment with tumor-controlling PDT regimens; this control was independent of anti-tumor immunity. The number of lung tumors present increases with the size of the primary $4 \mathrm{~T} 1$ and the amount of time the tumor is present in the animal [25]. Therefore, it is possible that the adaptive immune system-independent reduction in metastatic tumor growth is due to the absence of the primary tumor following surgical removal or treatment-induced reduction in primary tumor growth following treatment with the tumor growth-controlling PDT regimen.

Our studies support the use of an immune-enhancing PDT regimen as an adjuvant treatment that, when used in conjunction with therapies that inhibit or do not enhance immunity, has the potential to augment anti-tumor immunity. Recent studies have shown that PDT is an effective adjuvant therapy to surgery that increases the probability of long-term local disease control [1]. Friedberg and colleagues have demonstrated prolonged survival in malignant pleural mesothelioma patients treated with radical pleurectomy and intraoperative PDT [43] that the authors attribute in part to the immune effects of PDT.

In summary, we have identified an anti-tumor combination PDT treatment regimen that controls primary and metastatic tumor growth and enhances anti-tumor immunity. The combination therapy consists of treatment with an immune-enhancing PDT regimen followed 10 days later by treatment with a tumor growth-controlling treatment regimen. Treatment of both colon and mammary carcinomas showed similar host responses, and the host responses were independent of the photosensitizer used. These findings provide proof of principle for the use of PDT as an adjuvant therapy for enhancement of anti-tumor immunity that may be capable of controlling distant disease.

Acknowledgments This work was supported by National Cancer Institute Grants CA109480 and CA98156 and in part by the Roswell Park Cancer Center Support Grant CA16056.

Conflict of interest The authors declare that they have no conflict of interest.

Open Access This article is distributed under the terms of the Creative Commons Attribution License which permits any use, distribution, and reproduction in any medium, provided the original author(s) and the source are credited.

\section{References}

1. Agostinis P, Berg K, Cengel KA, Foster TH, Girotti AW, Gollnick SO, Hahn SM, Hamblin MR, Juzeniene A, Kessel D, Korbelik M, Moan J, Mroz P, Nowis D, Piette J, Wilson BC, Golab J (2011)
Photodynamic therapy of cancer: an update. CA Cancer J Clin 61:250-281

2. Henderson BW, Gollnick SO, Snyder JW, Busch TM, Kousis PC, Cheney RT, Morgan J (2004) Choice of oxygen-conserving treatment regimen determines the inflammatory response and outcome of photodynamic therapy of tumors. Cancer Res 64:2120-2126

3. Brackett CM, Gollnick SO (2011) Photodynamic therapy enhancement of anti-tumor immunity. Photochem Photobiol Sci 10:649-652

4. Mroz P, Hashmi JT, Huang YY, Lange N, Hamblin MR (2011) Stimulation of anti-tumor immunity by photodynamic therapy. Expert Rev Clin Immunol 7:75-91

5. Kousis PC, Henderson BW, Maier PG, Gollnick SO (2007) Photodynamic therapy (PDT) enhancement of anti-tumor immunity is regulated by neutrophils. Can Res 67:10501-10510

6. Korbelik M, Krosl G, Krosl J, Dougherty GJ (1996) The role of host lymphoid populations in the response of mouse EMT6 tumor to photodynamic therapy. Cancer Res 56:5647-5652

7. Abdel-Hady ES, Martin-Hirsch P, Duggan-Keen M, Stern PL, Moore JV, Corbitt G, Kitchener HC, Hampson IN (2001) Immunological and viral factors associated with the response of vulval intraepithelial neoplasia to photodynamic therapy. Cancer Res 61:192-196

8. Kabingu E, Vaughan L, Owczarczak B, Ramsey KD, Gollnick SO (2007) $\mathrm{CD}^{+} \mathrm{T}$ cell-mediated control of distant tumours following local photodynamic therapy is independent of $\mathrm{CD}^{+}$ $\mathrm{T}$ cells and dependent on natural killer cells. Br J Cancer 96: 1839-1848

9. Gollnick SO, Evans SE, Baumann H, Owczarczak B, Maier P, Vaughan L, Wang WC, Unger E, Henderson BW (2003) Role of cytokines in photodynamic therapy-induced local and systemic inflammation. Br J Cancer 88:1772-1779

10. Firczuk M, Nowis D, Golab J (2011) PDT-induced inflammatory and host responses. Photochem Photobiol Sci 10:653-663

11. Lu Z, Yuan L, Zhou X, Sotomayor E, Levitsky HI, Pardoll DM (2000) CD40-independent pathways of T cell help for priming of CD8(+) cytotoxic T lymphocytes. J Exp Med 191:541-550

12. Potter WR (1991) Photodynamic therapy of tumors a review of PDT dosimetry. In: Chester AN, Martellucci S, Scheggi AM (eds) Laser systems for photobiology and photomedicine, vol 252. Springer, Berlin, pp 165-170

13. Henderson BW, Daroqui C, Tracy E, Vaughan LA, Loewen GM, Cooper MT, Baumann H (2007) Cross-linking of signal transducer and activator of transcription 3-a molecular marker for the photodynamic reaction in cells and tumors. Clin Cancer Res 13:3156-3163

14. Gryshuk AL, Chen Y, Potter W, Ohulchansky T, Oseroff A, Pandey RK (2006) In vivo stability and photodynamic efficacy of fluorinated bacteriopurpurinimides derived from bacteriochlorophyll-a. J Med Chem 49:1874-1881

15. Williams MP, Ethirajan M, Ohkubo K, Chen P, Pera P, Morgan J, White WH III, Shibata M, Fukuzumi S, Kadish KM, Pandey RK (2011) Synthesis, photophysical, electrochemical, tumorimaging, and phototherapeutic properties of purpurinimide-Nsubstituted cyanine dyes joined with variable lengths of linkers. Bioconjug Chem 22:2283-2295

16. Gollnick SO, Liu X, Owczarczak B, Musser DA, Henderson BW (1997) Altered expression of interleukin 6 and interleukin 10 as a result of photodynamic therapy in vivo. Cancer Res 57:3904-3909

17. Barber DL, Wherry EJ, Ahmed R (2003) Cutting edge: rapid in vivo killing by memory CD8 T cells. J Immunol 171:27-31

18. Lethe B, Van den Eynde B, Van Pel A, Corradin G, Boon T (1992) Mouse tumor rejection antigens P815A and P815B: two epitopes carried by a single peptide. Eur J Immunol 22:2283-2288

19. Huang AYC, Gulden PH, Woods AS, Thomas MC, Tong CD, Wang W, Engelhard VH, Pasternack G, Cotter R, Hunt D, Pardoll 
DM, Jaffee E (1996) The immunodominant major histocompatibility complex class I-restricted antigen of a murine colon tumor derives from an endogenous retroviral gene product. Proc Natl Acad Sci USA 93:9730-9735

20. Cerosaletti KM, Blieden TM, Harwell LW, Welsh KM, Frelinger JG, Lord EM (1990) Alteration of the metastatic potential of Line 1 lung carcinoma cells: opposite effects of class I antigen induction by interferons versus DMSO of gene transfection. Cell Immunol 127:299-310

21. de Vree WJ, Essers MC, De Bruijn HS, Star WM, Koster JF, Sluiter W (1996) Evidence for an important role of neutrophils in the efficacy of photodynamic therapy in vivo. Cancer Res 56:2908-2911

22. Brackett CM, Muhitch JB, Evans SS, Gollnick SO (2013) IL-17 promotes neutrophil entry into tumor-draining lymph nodes following induction of sterile inflammation. J Immunol 191:4348-4357

23. Hryhorenko EA, Oseroff AR, Morgan J, Rittenhouse-Diakun K (1999) Deletion of alloantigen-activated cells by aminolevulinic acid-based photodynamic therapy. Photochem Photobiol 69:560-565

24. Mroz P, Szokalska A, Wu MX, Hamblin MR (2010) Photodynamic therapy of tumors can lead to development of systemic antigen-specific immune response. PLoS One 5:e15194

25. Aslakson CJ, Miller FR (1992) Selective events in the metastatic process defined by analysis of the sequential dissemination of subpopulations of a mouse mammary tumor. Cancer Res 52:1399-1405

26. Zeitouni NC, Paquette AD, Housel JP, Shi Y, Wilding GE, Foster TH, Henderson BW (2013) A retrospective review of pain control by a two-step irradiance schedule during topical ALA-photodynamic therapy of non-melanoma skin cancer. Lasers Surg Med 45:89-94

27. Gallucci S, Matzinger P (2001) Danger signals: SOS to the immune system. Curr Opin Immunol 13:114-119

28. Bianchi ME, Manfredi AA (2009) Immunology. Dangers in and out. Science 323:1683-1684

29. Garg AD, Krysko DV, Vandenabeele P, Agostinis P (2011) DAMPs and PDT-mediated photo-oxidative stress: exploring the unknown. Photochem Photobiol Sci 10:670-680

30. Garg AD, Nowis D, Golab J, Agostinis P (2010) Photodynamic therapy: illuminating the road from cell death towards antitumour immunity. Apoptosis 15:1050-1071

31. Korbelik M, Zhang W, Merchant S (2011) Involvement of damage-associated molecular patterns in tumor response to photodynamic therapy: surface expression of calreticulin and highmobility group box-1 release. Cancer Immunol Immunother 60:1431-1437
32. Panzarini E, Inguscio V, Dini L (2013) Immunogenic cell death: can it be exploited in PhotoDynamic Therapy for cancer? Biomed Res Int. doi:10.1155/2013/482160

33. Tracy EC, Bowman MJ, Henderson BW, Baumann H (2012) Interleukin-1alpha is the major alarmin of lung epithelial cells released during photodynamic therapy to induce inflammatory mediators in fibroblasts. Br J Cancer 107:1534-1546

34. Garg AD, Krysko DV, Vandenabeele P, Agostinis P (2012) Hypericin-based photodynamic therapy induces surface exposure of damage-associated molecular patterns like HSP70 and calreticulin. Cancer Immunol Immunother 61:215-221

35. Kaech SM, Wherry EJ (2007) Heterogeneity and cell-fate decisions in effector and memory CD8 $+\mathrm{T}$ cell differentiation during viral infection. Immunity 27:393-405

36. Brinkman CC, Peske JD, Engelhard VH (2013) Peripheral tissue homing receptor control of naive, effector, and memory CD8 T cell localization in lymphoid and non-lymphoid tissues. Front Immunol. doi:10.3389/fimmu.2013.00241

37. Masopust D, Schenkel JM (2013) The integration of T cell migration, differentiation and function. Nat Rev Immunol 13:309-320

38. Kabingu E, Oseroff AR, Wilding GE, Gollnick SO (2009) Enhanced systemic immune reactivity to a basal cell carcinoma associated antigen following photodynamic therapy. Clin Cancer Res 15:4460-4466

39. Mroz P, Vatansever F, Muchowicz A, Hamblin MR (2013) Photodynamic therapy of murine mastocytoma induces specific immune responses against the cancer/testis antigen P1A. Cancer Res 73:6462-6470

40. Gomer CJ, Ferrairo A, Murphree AL (1987) The effect of localized porphyrin photodynamic therapy on the induction of tumour metastasis. Br J Cancer 56:27-32

41. Blank M, Lavie G, Mandel M, Keisari Y (2000) Effects of photodynamic therapy with hypericin in mice bearing highly invasive solid tumors. Oncol Res 12:409-418

42. Castano AP, Gad R, Zahra T, Hamblin MR (2003) Specific antitumor immune response with photodynamic therapy mediated by benzoporphyrin derivative and chlorin(e6). In Jacques SL, Duncan DD, Kirkpatrick SJ Kriete A (eds) Laser-tissue interaction XIV, Proceedings of SPIE, vol 4961. SPIE, WA, pp 1-9

43. Friedberg JS, Culligan MJ, Mick R, Stevenson J, Hahn SM, Sterman D, Punekar S, Glatstein E, Cengel K (2012) Radical pleurectomy and intraoperative photodynamic therapy for malignant pleural mesothelioma. Ann Thorac Surg 93:1658-1665 